\title{
KRAFT SCRAP PAPER PULP AS A SUBSTITUTE OF WOOD CHIPS IN MANUFACTURE OF PARTICLEBOARDS RESINATED WITH HYBRID PF/pMDI RESIN
}

\author{
Dorota Dukarska ${ }^{1, \star}$, Katarzyna Buszka ${ }^{1}$, Izabela Modzelewska ${ }^{2}$
}

\begin{abstract}
This study analyzed feasibility of manufacture of composite particleboards resinated with a mixture of phenol-formaldehyde resin and 4,4'-methylenediphenyl isocyanate in the weight ratio 70:30. For this purpose 3-layer particleboards were produced with varying shares of Kraft scrap paper pulp in the core. Experimental boards were manufactured applying 0, 10, 15, 25, 50 and $75 \%$ substitution of wood chips with Kraft paper pulp. Analyses were conducted to determine physico-mechanical properties of boards, i.e. bending strength, modulus of elasticity, internal bond before and after the boiling test and swelling in thickness after 24 soaking in water. Based on recorded testing results it was stated that moisture resistant composite boards manufactured with a $25 \%$ substitution of wood chips with Kraft paper pulp meet the requirements of the EN 312 standard for boards used in humid conditions in terms of their strength and moisture resistance specified in the internal bond after the boiling test.
\end{abstract}

Keywords: Mechanical properties, utilization, waste paper, water resistance, wood composites.

\section{INTRODUCTION}

Requirements of sustainable wood management make it necessary to search for alternative raw materials for manufacture of particleboards. Some of the well-established alternatives include annual crop residue as a substitute of wood chips in particleboard production (Boquillon et al. 2004, Czarnecki and Dukarska 2010, Azizi et al. 2011, Dukarska et al. 2011, Dukarska et al. 2012, Park et al. 2012, Dukarska et al. 2015, Dziurka et al. 2015, de Melo et al. 2015, Kord et al. 2016). Utilization of annual crop residue brings obvious benefits, such as reduced wood consumption having a positive effect on board prices, as well as management of plant-origin waste. Its application is connected with certain problems when used in commercial scale production processes. These crops are harvested seasonally. A lack of permanent availability of annual plant material leads to the need to accumulate and store its huge quantities over relatively long time periods. Moreover, the specific character of methods applied to harvest annual crops results in relatively large amounts of mineral contamination originating e.g. from the soil. This requires additional operations in the preparation of stock materials for the manufacture of particleboards in order to purify the raw material.

\footnotetext{
${ }^{1}$ Department of Wood Based Materials, Faculty of Wood Technology, Poznań University of Life Sciences, Wojska Polskiego, Poznań, Poland.

${ }^{2}$ Institute of Chemical Wood Technology, Faculty of Wood Technology, Poznań University of Life Sciences, Wojska Polskiego, Poznań, Poland.

•Corresponding author: ddukar@up.poznan.pl

Received: 22.10.2016 Accepted: 26.11.2017
} 
Increasing public awareness of environmental protection issues and the need for selective waste collection result in improved efficiency of waste acquisition, including recycled paper. Such waste is used mainly in the pulp and paper industry; however, paper production using scrap paper is connected with numerous technological problems. When preparing pulp from scrap paper it is necessary to remove all chemicals used in the production process, such as glues, pigments, preservatives as well as printing inks and toners. Such processing results in adverse changes, e.g. reduced strength of cellulose fibers, leading to a deterioration of quality and strength of paper produced from such processed raw materials. We also need to remember that recycling, storage, deinking or decontamination of paper waste generate considerable costs and may cause negative environmental impacts (Kim et al. 2009, Kordkheili et al. 2012, Lykidis et al. 2012). Irrespective of the applied technologies we are still left with certain amounts of paper waste, which will not be utilized due to economic and technological reasons (Lykidis et al. 2012). The situation is completely different when considering potential utilization of paper in wood based material industry. This is connected with the fact that the board industry has gradually adapted to using raw materials of increasingly inferior quality, including waste materials. Adaptation of board manufacturing technologies to the utilization of scrap paper should be easier to implement than in paper production (Nicewicz et al. 2006). Apart from environmental factors, application of paper in the manufacture of wood based materials seems to be interesting for two reasons. On the one hand, non-recycled paper waste constitutes currently abundant unmanaged resources of raw material, while on the other hand the use of paper waste in manufacture is much cheaper than board production solely from fresh wood material (Lykidis et al. 2012). In contrast to annual crop residue, in the case of paper waste there are no problems posed by seasonal availability or the necessity to store its large quantities. At appropriate organization it would obviously be possible to ensure a continuous supply of this raw material. Despite numerous research papers published on the potential paper recycling, a limited number of studies concern the utilization of scrap paper in the production of particleboards. Studies conducted to date have investigated mainly scrap paper coming from packaging, newspaper and office paper. The type of used waste has a significant effect on board properties (Massijaya and Okuma 2005, Tikhonova et al. 2014). It was shown that when applying urea-formaldehyde (UF) and melamine-urea-formaldehyde (MUF) resins single-layer particleboards with required properties may be produced with a 50\% share of scrap paper for MUF resin and a $30 \%$ share for UF resin (Nicewicz et al. 2006). Increasing the share of paper waste in the board over 50\% results in a drastic reduction of their physical and mechanical properties. For such a considerable rate of wood chip substitution with Kraft scrap paper it is advisable to increase resination rate. A study by Eshraghi and Khademieslam (2012) showed that a slight increase in resination rate (from $9 \%$ to $10 \%$ ) first of all improves internal bond of such boards and limits their swelling in thickness after $24 \mathrm{~h}$ soaking in water. The importance of the optimal resination rate was also confirmed by a study of Taramian et al. (2007), in which paper mill sludge was used to produce general purpose boards. Board properties may also be improved by increasing their density (Lykidis et al. 2012) or modifying paper with maleic anhydride (Nourbakhsh and Ashori 2010). Introduction of fibers retrieved from OCC waste in face layers of particleboards improves quality of their surface by reducing its roughness (Abdolzadeh and Doosthoseini 2009). Another method to improve properties of particleboards manufactured using scrap paper is to modify UF resin using pMDI. Substitution of UF resin with pMDI at $2-4 \%$ considerably improves strength properties and moisture resistance of boards manufactured with both a $30 \%$ and $50 \%$ share of OCC paper waste (Lykidis et al. 2012). In turn, the use of pMDI alone makes it possible to manufacture boards with a $50 \%$ share of waste paper from newspapers, magazines and office paper. Such boards are characterized by relatively attractive appearance and thus they may be used in interior design, e.g. as siding and partitioning material (Grigoriou 2003).

In view of the development of particleboard production and the need to utilize waste the aim of this study was to investigate the feasibility of manufacturing moisture resistant composite particleboards using Kraft paper waste. Moreover, another aim of this study was also to determine the effect of wood chip substitution in the core of particleboards with Kraft paper waste on physicomechanical properties of boards resinated with hybrid PF/pMDI resin. A review of literature on the application of paper waste in particleboard production shows that in most studies amine resins and pMDI were used. For this reason the authors of this study investigated the potential production of such particleboards using phenol-formaldehyde (PF) resin and 4,4'-methylenediphenyl isocyanate (pMDI). 


\section{MATERIALS AND METHODS}

Experimental boards were manufactured using industrial pine chips and microchips as well as ground Kraft waste paper pulp. Paper used in the tests was manufactured from unbleached pine Kraft pulp (produced by Mondi Swiecie S.A., Poland). Scrap sheets after being trimmed to smaller size were ground using a laboratory grinder. Parameters of Kraft paper, which waste was used in studies, were determined based on the binding technical standards and presented in Table 1.

Table 1. Selected strength properties of tested paper.

\begin{tabular}{|l|l|l|l|}
\hline Parameter & Test method & Unit & Value \\
\hline Surface & - & - & ribbed \\
\hline Grammage & ISO 536:2012 & $\mathrm{g} / \mathrm{m}^{2}$ & $200 \pm 5$ \\
\hline SCT & ISO 9895:2008 & $\mathrm{kN} / \mathrm{m}$ & 3,7 \\
\hline Tensile strength & ISO 1924-2: 2008 & $\%$ & 2,9 \\
\hline Breaking length & ISO 1924-2: 2010 & $\mathrm{km}$ & 8,5 \\
\hline Tensile stiffness & ISO 1924-2: 2010 & $\mathrm{kN} / \mathrm{m}$ & 780 \\
\hline Burst & ISO 2758:2014 & $\mathrm{kPa}$ & 570 \\
\hline Tearing resistance & ISO 1974: 2012P & $\mathrm{mN}$ & 1080 \\
\hline Air permeability & ISO 9073-15:2008 & $\mathrm{s}$ & 46 \\
\hline
\end{tabular}

Table 2, Figure 1 and Figure 2 present comparisons of parameters of wood chips in the core of the boards and paper particles, determined based on dimensional analyses. Sieve analysis was also applied to determine the fraction composition, as presented in Figure 1.

A formulation produced by mixing phenol-formaldehyde (PF) resin (produced by LERG SA, Poland) and 4,4'-methylenediphenyl isocyanate (pMDI) (from Bayer AG, Germany) in the weight ratio $70: 30$ was used as a binding agent. Parameters of PF resin were as follows: viscosity at $25^{\circ} \mathrm{C}-735$ $\mathrm{mPas}$, density $-1,215 \mathrm{~kg} / \mathrm{m}^{3}$, solids content $-46,8 \% \mathrm{pH}-8,78$ and gel time at $130^{\circ} \mathrm{C}-275 \mathrm{~s}$. In turn, properties of pMDI were as follows: solids content $-100 \%$, NCO content $-31 \%$, viscosity at $25^{\circ} \mathrm{C}-220$ $\mathrm{mPas}$ and hydrolytic chlorine $-96 \mathrm{mg} / \mathrm{kg}$.

Three-layer experimental boards were produced under laboratory conditions adopting the following parameters: board thickness $19 \mathrm{~mm}$, resination rate of the face and core layers $8 \%$ (based on dry mass of raw materials) and board density $700 \mathrm{~kg} / \mathrm{m}^{3}$. Chips of the core layer were partially substituted with Kraft paper particles at $0,10,15,25,50$ and $75 \%$. The face layers was produced using microwood chips only.

Table 2. Dimensional analysis and the shape of average wood and paper particles.

\begin{tabular}{|l|l|l|l|l|l|l|}
\hline \multirow{2}{*}{$\begin{array}{l}\text { Type of } \\
\text { particles }\end{array}$} & \multicolumn{7}{|c|}{ Parameter } \\
\cline { 2 - 7 } & $\mathrm{l}$ & $\mathrm{a}$ & $\mathrm{b}$ & 1 & $\mathrm{y}$ & $\mathrm{m}$ \\
\hline \multirow{2}{*}{ Wood } & $(\mathrm{mm})$ & $(\mathrm{mm})$ & $(\mathrm{mm})$ & - & - & - \\
\hline \multirow{2}{*}{ Kraft paper } & 13,66 & 0,84 & 1,59 & 16,26 & 1,89 & 8,59 \\
& $(3,89)$ & $(0,36)$ & $(0,61)$ & $(5,72)$ & $(0,99)$ & $(1,93)$ \\
\hline & 11,92 & 0,72 & 6,57 & 17,51 & 10,05 & 1,86 \\
& $(2,34)$ & $(0,21)$ & $(1,93)$ & $(6,35)$ & $(3,57)$ & $(0,56)$ \\
\hline
\end{tabular}

1-length, a-thickness, b-width, $\lambda$-slenderness ratio, $\psi$-flatness ratio, $m$-width factor,

()- standard deviation. 


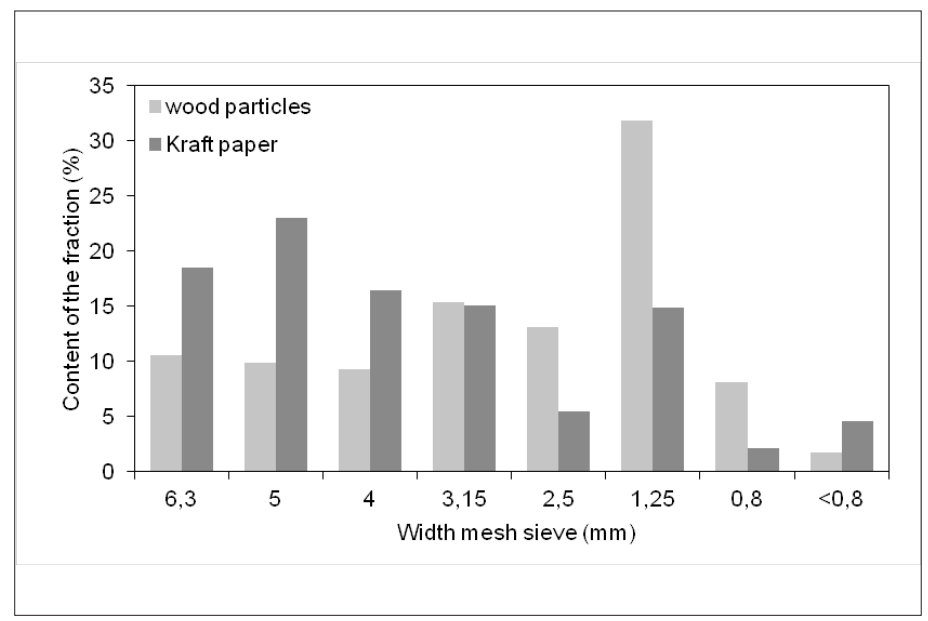

Figure 1. Fraction composition of wood chips in the core and Kraft paper particles.

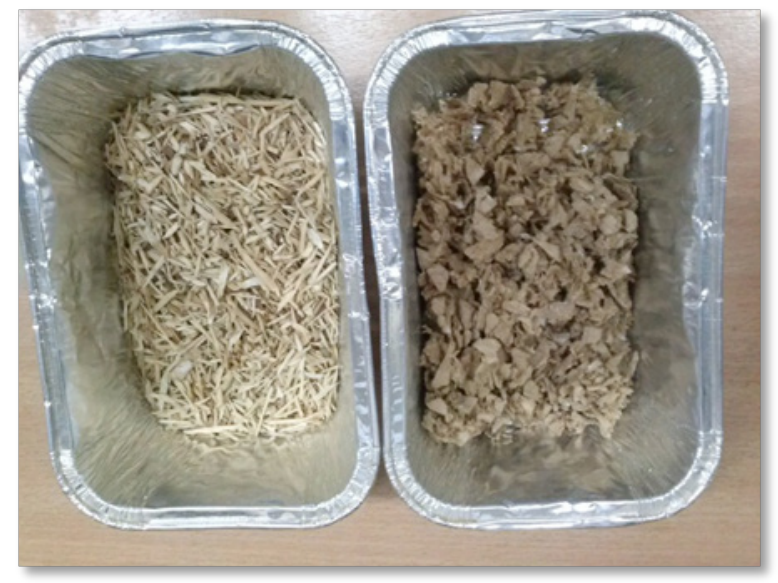

Figure 2. Fractions of wood chips in the core and Kraft paper particles with the greatest fraction in the material.

Boards were pressed at a temperature of $200^{\circ} \mathrm{C}$ at unit pressure of 2,5 Mpa for $23 \mathrm{~s} / \mathrm{mm}$ board thickness. Experimental boards were tested to determine their physical and mechanical properties in accordance with binding technical standards, recording their static bending strength as modulus of rigidity (MOR) and modulus of elasticity at bending (MOE) according to the EN 310 standard, internal bond (IB) according to EN 319, internal bond after the boiling test (V100) according to EN 1087-1 and swelling in thickness after $24 \mathrm{~h}$ soaking in water (TS) according to EN 317.

In order to explain fluctuations in recorded values of strength parameters images of surface structure of chips and paper particles after resination were analyzed. These images were recorded using a digital camera and a VITINY VT 300 electronic microscope at a 40x magnification.

Results of tests for physico-chemical properties of manufactured experimental boards were analyzed statistically using STATISTICA ver. 10 software. To compare means of physico-mechanical properties for the tested boards a one-way analysis of variance was conducted and Tukey's post hoc test was used to identify homogeneous groups of means for each analyzed property assuming the boundary value for the significance level $\mathrm{p}$ of 0,05 . When analyzing recorded results the particleboard produced solely from wood chips was used as the reference sample. 10 samples per 
board for each property were tested in order to evaluate the mean value and standard deviation.

\section{RESULTS AND DISCUSSION}

Based on testing results given in Table 3, Figure 3 and Figure 4 it may generally be stated that board strength and moisture resistance deteriorates with an increase in the substitution of wood chips in the core of particleboards with Kraft paper waste. This is particularly evident at the share of paper waste in the core exceeding $25 \%$. At a lower rate of paper particles in the board no significant changes were recorded in bending strength (MOR) and modulus of elasticity (MOE). Tukey's test conducted for homogeneous groups identified the same homogeneous group $a$, for which the level of statistical significance $p$ assumed values exceeding the adopted level of 0,05 . An increase in the substitution rate to $50 \%$ as a consequence results in a reduction of bending strength on average by $30 \%$, while for the modulus of elasticity it is by $20 \%$ (homogeneous group c). As a result of such a marked deterioration of bending strength these boards do not meet the requirements of the EN 312

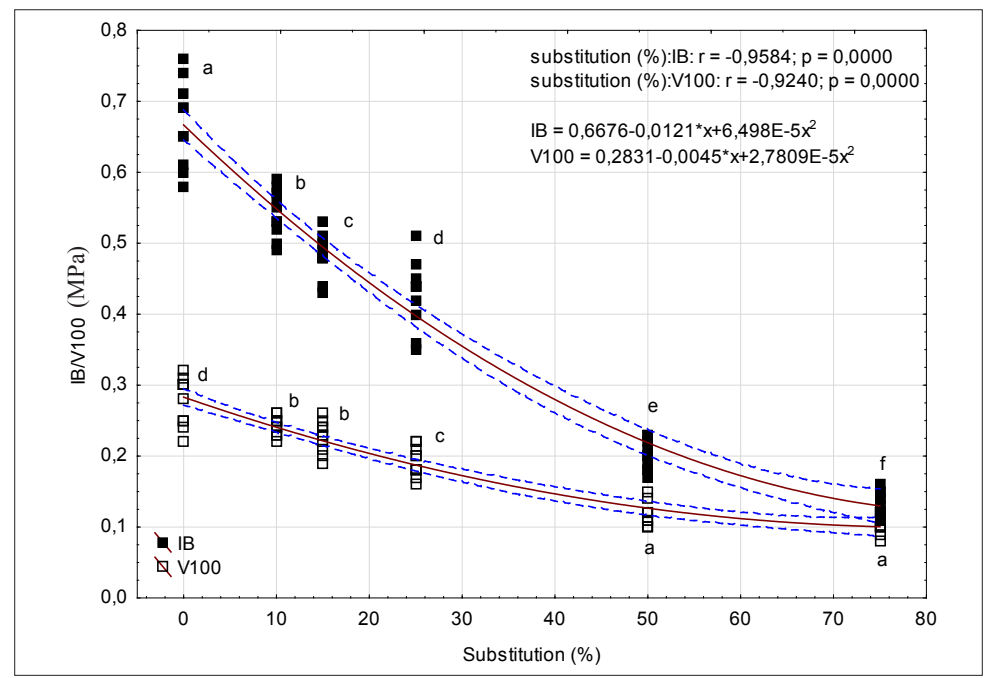

Figure 3. A graph for the scatter of recorded values for internal bond (IB) before and after the boiling test (V100).

Table 3. Bending strength and modulus of elasticity of particleboards manufactured with various shares of Kraft paper waste.

\begin{tabular}{|l|l|l|}
\hline Substitution degree & MOR & MOE \\
\hline$(\%)$ & $(\mathrm{MPa})$ & $(\mathrm{MPa})$ \\
\hline 0 & $15,81(1,00) \mathrm{a}$ & $2540(190) \mathrm{a}$ \\
\hline 10 & $15,76(0,37) \mathrm{a}$ & $2550(180) \mathrm{a}$ \\
\hline 15 & $15,31(1,90) \mathrm{a}$ & $2530(200) \mathrm{a}$ \\
\hline 25 & $14,93(0,45) \mathrm{a}$ & $2500(190) \mathrm{a}$ \\
\hline 50 & $11,00(1,41) \mathrm{c}$ & $2050(150) \mathrm{c}$ \\
\hline 75 & $8,54(1,24) \mathrm{b}$ & $1400(150) \mathrm{b}$ \\
\hline
\end{tabular}

Standard for boards used in humid conditions, i.e. P3, for which the boundary value is $14 \mathrm{MPa}$. Internal bond (IB) takes different values, which are presented in Figure 3. An increase in the content of paper particles in the board results in a gradual decrease in IB values. At a 25\% share of paper particles internal bond decreased by approx. $40 \%$. Despite such a considerable deterioration of this strength parameter boards containing such an amount of paper waste met requirements for boards used in humid conditions P3. An increase in the substitution rate of wood chips with paper particles to $50 \%$ and $75 \%$ causes a drastic decrease in IB values by $70-80 \%$ and disqualifies such boards from being used under humid conditions. Statistical analysis showed that the substitution rate of wood chips in the core 
using paper particles has a significant effect on tensile strength of boards. This was confirmed by the results of Tukey's test providing as many as six different homogeneous groups for each substitution rate separately (intergroup MS $=0,0011 ; \mathrm{df}=54, \mathrm{p}<0,05$ ), as well as a high correlation coefficient between substitution rates and IB values. Slightly lower differences were recorded for tensile strength recorded after the boiling test (the V100 test). Substitution at 10 and 15\% caused a reduction of board strength after the boiling test by $14 \%$ and $17 \%$, respectively, while the post host test showed no statistically significant differences between these values (homogeneous group b). Increasing the substitution rate to $25 \%$ resulted in a decrease of the value recorded in the V100 test in relation to the reference board by $30 \%$. Nevertheless, boards containing the same amount of Kraft paper meet the requirements imposed on P3 boards. Increasing the amount of paper in the particleboard to 50 and $75 \%$ caused a further reduction of tensile strength after the boiling test to 0,12 and $0,10 \mathrm{MPa}$, respectively. These values fall below the limit required for $\mathrm{P} 3$ boards, i.e. $0,13 \mathrm{MPa}$. Analysis of homogeneous groups showed no significant differences between values from the V100 test recorded for these two substitution rates - homogeneous group a.

The reduction of tensile strength both before and after the boiling test was accompanied by a relatively slight decrease in moisture resistance manifested in swelling in thickness after extended exposure to water. However, it needs to be stressed that none of the tested boards met requirements of the standard in terms of swelling in thickness after $24 \mathrm{~h}$ soaking in water. Thickness swelling (TS) admissible by the standard for P3 boards is $14 \%$, while manufactured experimental boards depending on the substitution rate showed swelling of $16,5 \%$ in relation to the reference board and $22,9 \%$ for the board with a $75 \%$ share of Kraft paper. Such a level of swelling in tested boards may be explained by the fact that no hydrophobic agents, typically used in commercial-scale production of particleboards, were used in the manufacture of experimental boards. Nevertheless it was found that at a maximum substitution of wood chips with Kraft paper particles the TS value decreased by approx. $16 \%$ in relation to the reference board (Figure 4). A decrease in board strength and moisture resistance as a result of substitution of wood chips with paper waste is connected with the specific surface and dimensions of paper particles. They have a smaller thickness and greater width (Table 2, Figure 2) and thus also a greater area per unit of mass in comparison to wood chips. This results in the formation of a smaller number of glue lines on their surface and as a consequence their lesser gluability in comparison to wood chips. Properties of boards manufactured with different shares of Kraft paper, particularly their internal bond and swelling, are also affected by the layer structure of paper and its tensile strength inferior in comparison to that of wood and resulting from the weaker fiber binding forces. Due to the structure of paper and its defibrability paper surface is defibrated when paper is ground. This disturbs resination of a mixture of paper particles and wood chips, causing excessive deposition of adhesive solution on these fibers. This is confirmed by the analysis of images presenting resinated surfaces of paper particles given in Figure 5a and Figure 6a. Such a deposition of glue on fiber surface hinders its penetration inside paper structure, thus reducing binding force of paper particles. This effect was not observed in the case of wood chips that have a more compact surface structure than paper chips. As evidenced by Figure $5 \mathrm{~b}$ and Figure $6 \mathrm{~b}$, gluing and mixing the chips allowed for considerably better distribution of the adhesive droplets on their surface. As a result, the adhesive was more evenly spread on the chip surface.

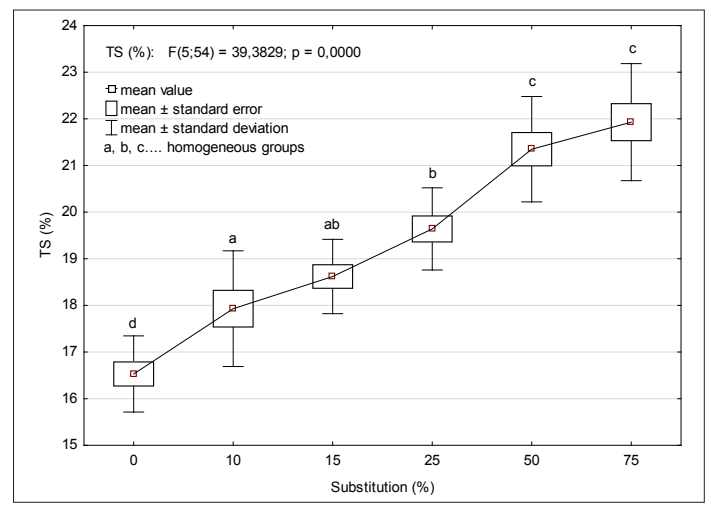

Figure 4. Swelling in thickness of particleboards with varying shares of Kraft paper waste after $24 \mathrm{~h}$ soaking in water. 
According to Lykidis et al. (2012) the negative effect of paper waste on board properties is caused by pulping-related chemical, physical and structural changes in fibers within the cell wall and probably also by the presence of inorganic substances, resulting in the deterioration of mechanical properties of paper. In the opinion of the authors it is also essential that tensile strength of stratified papers to a considerable extent depends on their moisture content - the higher the paper moisture content, the lesser their strength (Przybysz 1997). In the resination process a certain amount of water is introduced with PF/pMDI resin causing an increase in moisture content in both wood chips and paper, and as a result - a deterioration of their tensile strength. Thus parameters of the resination process need to be optimized in order to improve physicomechanical properties of particleboards manufactured with the addition of Kraft paper. In the case of conventional particleboards this is achieved by increasing the resination rate of wood chips. However, it seems that a better solution is provided by increasing the particles and wood chips, but also reduces the amount of water introduced in the process of their resination using PF resin.
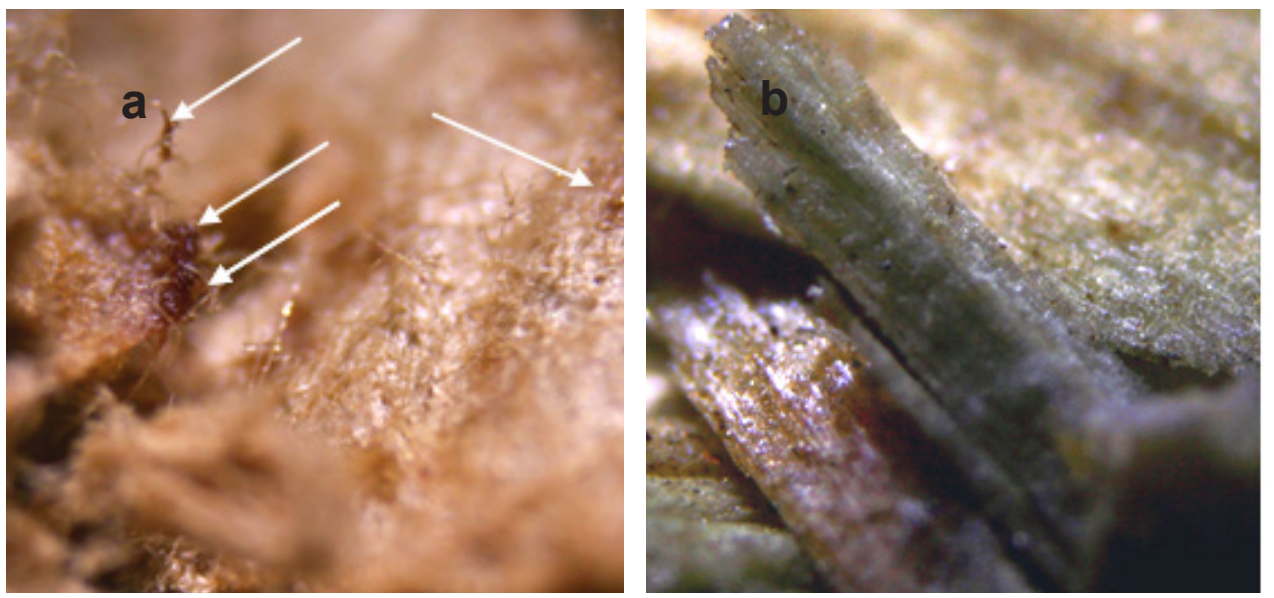

Figure 5. An image of surface of a mixture of Kraft paper particles (a) and wood chips (b) following resination with $\mathrm{PF} / \mathrm{pMDI}$.
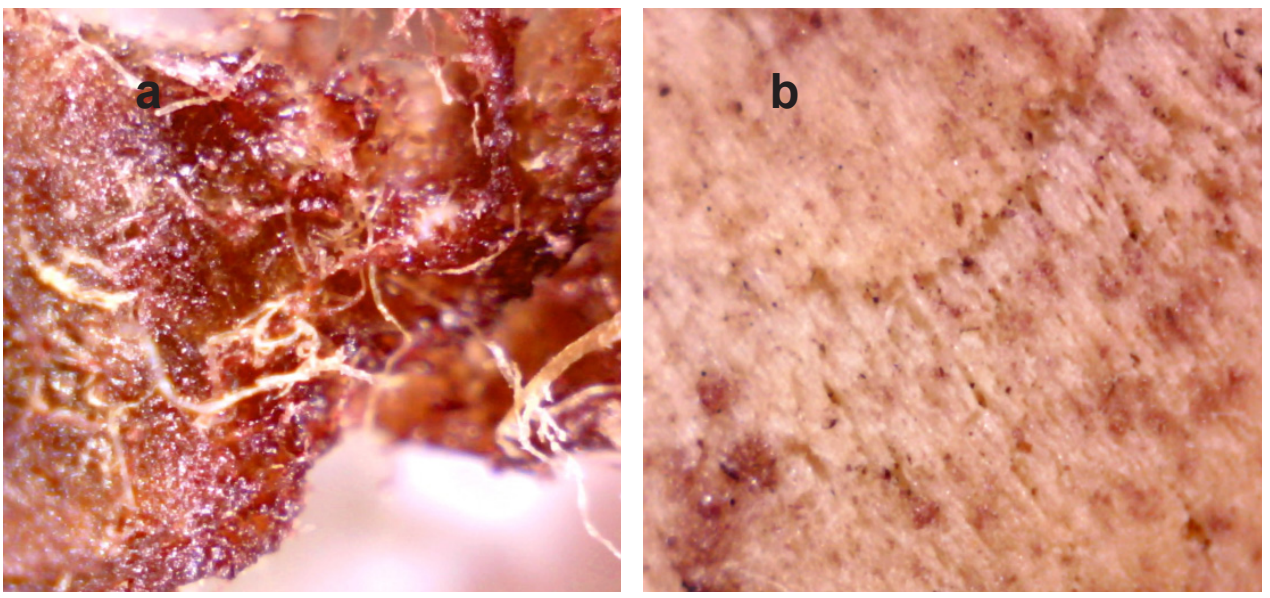

Figure 6. An image of surface of a single Kraft paper particle (a) and a wood chip (b) following resination with $\mathrm{PF} / \mathrm{pMDI}$. 


\section{CONCLUSIONS}

Summing up it may be stated that moisture resistant composite boards may be produced with a share of Kraft paper as a partial substitute of wood chips in the core of particleboards. The application of such waste in the manufacture of particleboards, despite their resination with a mixture of PF resin and pMDI, considerably reduces physico-mechanical properties of tested composite boards. Nevertheless, boards manufactured with a $25 \%$ share of paper both in terms of strength and moisture resistance determined in the V-100 test met the requirements of the EN 312 standard for non-load bearing particleboards for use in humid conditions, i.e. grade P3. A greater substitution rate causes a drastic reduction of all physico-mechanical properties of boards to the level preventing their application under humid conditions. In order to increase the substitution rate of wood chips with particles of Kraft paper waste it is necessary to increase the share of pMDI in the glue mixture. Moreover, similarly as in the case of commercial-scale production, to ensure a smaller swelling in such boards hydrophobic agents need to be applied, reducing the tendency to thickness changes at long-term exposure to moisture. Results of the study are fully consistent with those reported by other authors of studies on the application of waste of other paper types in the manufacture of particleboards.

\section{REFERENCES}

Abdolzadeh, H.; Doosthoseini, K. 2009. Evaluation of old corrugated container and wood fiber application on surface roughness of three-layer particleboard. BioResources 4(3): 970-978.

Azizi, K.; Tabarsa, T.; Ashori, A. 2011. Performance characterizations of particleboards made with wheat straw and waste veneer splinters. Composites: Part B 42(7): 2085-2089.

Boquillon, N.; Elbez, G.; Schönfeld U. 2004. Properties of wheat straw particleboards bonded with different types of resin. Journal of Wood Science 50(3): 230-235.

Czarnecki, R.; Dukarska, D. 2010. Estimating the possibilities of applying Sida hermaphrodita Rusby to the production of low-density particleboards. Annals of Warsaw University of Life Science SGGW, Forest and Wood Technology 71: 83-86.

Dukarska, D.; Łęcka, J.; Szafoni, K. 2011. Straw of white mustard (Sinapis alba) as an alternative raw material in the production of particle boards resinated with UF resin. Acta Scientiarum Polonorum, Silvarum Colendarum Ratio et Industria Lignaria (10): 21-28.

Dukarska, D.; Lęcka, J.; Czarnecki, R. 2012. The effect of wood chip substitution with evening primrose waste on properties of particleboards depending on the type of binding agent. Electronic Journal of Polish Agricultural Universities (EJPAU) 15(2): 5-5.

Dukarska, D.; Bartkowiak, M.; Stachowiak - Wencek A. 2015. White mustard straw as an alternative raw material in the manufacture of particleboards resinated with different amount of urea formaldehyde resin. Drewno 58(194): 49-63.

Dziurka, D.; Mirski, R.; Dukarska, D.; Derkowski, A. 2015. Possibility of using the expanded polystyrene and rape straw to the manufacture of lightweight particleboards. Maderas-Cienc Tecnol 17(3): 647-656.

European Standard EN 310. 1993. Wood based panels. Determination of modulus of elasticity in bending and of bending strength. CEN European Committee for Standardisation. 
European Standard EN 312. 2005. Particleboards - specifications. CEN European Committee for Standardisation.

European Standard EN 317. 1993. Particleboards and fiberboards. Determination of swelling in thickness after immersion in water. CEN European Committee for Standardisation.

European Standard EN 319. 1993. Determination of tensile strength perpendicular to the plane of the board. CEN European Committee for Standardisation.

European Standard EN 1087-1. 1995. Particleboards - Determination of moisture resistance Boil test. CEN European Committee for Standardisation.

Eshraghi, A.; Khademieslam, H. 2012. Waste paperboard in composition panels. Cellulose Chemistry and Technoogy. 46 (9-10): 637-642.

Grigoriou, A.H. 2003. Waste paper-wood composites bonded with isocyanate. Wood Science and Technology 37(1): 79-89.

ISO 536. 2012. Paper and board - Determination of grammage. International Organization for Standardization.

ISO 1924-2. 2008. Paper and board - Determination of tensile properties - Part 2: Constant rate of elongation method (20 mm/min). International Organization for Standardization.

ISO 1924-2. 2010. Paper and board - Determination of properties by the action of tensile forces Part 2: Testing at constant stretching speed $(20 \mathrm{~mm} / \mathrm{min})$. International Organization for Standardization.

ISO 1974. 2012P. Paper - Determination of tearing resistance - Elmendorf method. International Organization for Standardization.

ISO 2758. 2014. Paper - Determination of bursting strength. International Organization for Standardization.

ISO 9073-15. 2008. Textiles - Test methods for nonwovens - Part 15: Air permeability. International Organization for Standardization.

ISO 9895. 2008. Paper and board - Compressive strength - Short-span test. International Organization for Standardization.

Kim, S.; Kim, H.J.; Park, J.C. 2009. Application of recycled paper sludge and biomass materials in manufacture of green composite pallet. Resources Conservation and Recycling 53(12): 674-679.

Kord, B.; Zare, H.; Hosseinzadeh, A. 2016. Evaluation of the mechanical and physical properties of particleboard manufactured from canola (Brassica napus) straws. Maderas- Cienc Tecnol 18(1): 9-18.

Kordkheili, H.Y.; Behrooz, R.; Jalilvand, M. 2012. Using industrial waste of old corrugating containers paper recycling mill in composite panels manufacturing. Journal of Reinforced Plastics and Composites 31(12): 855-860.

Lykidis, C.; Parnavela, C.; Goulounis, N.; Grigoriou, A. 2012. Potential for utilizing waste corrugated paper containers into wood composites using UF and PMDI resin systems. European Journal of Wood and Wood Products 70: 811-818.

Massijaya, M.Y.; Okuma, M. 2005. Comparisons of boards properties made from different waste papers. Edited by: Winandy, JE; Wellwood, RW; Hiziroglu, S. Conference: $22^{\text {nd }}$ World Congress of the 
International-Union-of-Forest-Research-Organizations Location: Brisbane, AUSTRALIA Date: AUG 08-13. 2005.

de Melo, R.R.; Stangerlin, D.M.; Santana, R.R.C.; Pedrosa, T.D. 2015. Decay and termite resistance of particleboard manufactured from wood, bamboo and rice husk. Maderas- Cienc Tecnol 17(1): 55-62.

Nicewicz, D.; Pawlicki, J.; Borysiuk, P.; Zado, A. 2006. Application of waste paper in manufacturing of particleboards. Acta Scientiarum Polonorum, Silvarum Colendarum Ratio et Industria Lignaria 5(1): 163-171.

Nourbakhsh, A.; Ashori, A. 2010. Particleboard made from waste paper treated with maleic anhydride. Waste Management \& Research 28(1): 51-55.

Park, H.J.; Oh, S.W.; Wen, M.Y. 2012. Manufacture and properties of miscanthus-wood particle composite boards. Journal of Wood Science 58(5): 459-464.

Przybysz, K. 1997. Pulp and paper technology. Paper Technology [in Polish]. Wydawnictwo Szkolne i Pedagogiczne, Warszawa.

Taramian, A.; Doosthoseini, K.; Mirshokraii, S.A.; Faezipour, M. 2007. Particleboard manufacturing: an innovative way to recycle paper sludge. Waste Management 27(12): 1739-1746.

Tikhonova, E.; Lecourt, M.; Irle, M. 2014. The potential of partial substitution of the wood fibre in hardboards by reject fibers from the paper recycling industry. European Journal of Wood and Wood Products 72: 177-184. 